\title{
PRIMEIRO SUPLEMENTO À LISTA DOS NOMES VULGARES DE PEIXES DE ÁGUAS DOCES E SALÔBRAS DA ZONA SÊCA DO NORDESTE E LESTE DO BRASIL
}

\author{
Rui Simões de Menezes \\ (Serviço de Piscicultura - Dept. de Sêcas \\ - Fortaleza, Ceará, Brasil).

\section{1 - INTRODUÇÃO}

Em outubro de 1948, o autor enviou, para publicação no volume especial dos "Arquivos do Museu Nacional", em homenagem a ALípio de Miranda Ribeiro, os originais de um trabalho intitulado "Lista dos nomes vulgares de peixes de águas doces e salôbras da zona sêca do Nordeste e Leste do Brasil'.

Vem o autor acumulando, a partir daquela data, novos verbetes, os quais, agrupados abaixo por ordem alfabética, constituem o "Primeiro Suplemento à Lista dos Nomes Vulgares de Peixes de águas doces e salôbras da zona sêca do Nordeste e Leste do Brasil"'.

2 - PRIMEIRO SUPLEMENTO À LISTA DOS NOMES VULGARES DE PEIXES DE ÁGUAS DOCES E SALÔBRAS DA ZONA SECA DO NORDESTE E LESTE DO BRASIL

ARENGUE - Corruptela de ARENQUE. Palmeirais, Piauí.

BOCA LARGA - Miguel Alves, Piauí. No ano de 1948: produção de $1.000 \mathrm{k}$, no valor de $\operatorname{Cr} \$ 4.000,00$.

BOUCA DE SAPO - Beneditinos, Piauí.

BRANQUIM - Corruptela de BRANQUINHO ou BRANQUINHA. Iguatú, Ceará, onde, em 1947, foram pescados 428 k, no valor de Crế 1.626,40. Peixe de escama, fam. Characidae, subfam. Curimatinae.

CANDONGO - Peixe dágua doce, rio Cocó (Fortaleza, Ceará). Apanhado à profundidade de $0,50 \mathrm{~m}$ (ANôNimo, 1928: 17).

CANGACEIRO - Mesmo que CANGATÍ, no açude público "Cru* zêta", Rio Grande do Norte. 
CANGAIA - Mesmo que CANGATí, no açude público "Cruzêta".

CASCUDO BARBUDO - No açude "Cruzêta", Rio Grande do Norte, corresponde a um peixe do gên. Plecostomus.

CASCUDO JUREMÊRO - No açude "Cruzêta", Rio Grande do Norte, consoante descrição dos pescadores, corresponde a um peixe do gên. Loricaria. Segundo opinião do Dr. Antônio Carlos Estevẽo de Oliveira (Serv. Piscicultura, D. N. O. C. S.), o nome "JUREMêRO pode derivar de jurema", Mimosa sp, planta da fam. Mimosaceae, espinhosa, por analogia com os espículos que revestem as placas do tegumento superior dos peixes do gên. Loricaria. Sousa (1945, 2: 69-70). "Geremari é outra árvore, que dá pela terra a dentro, a qual é delgada no pé e muito grossa em cima; dá uma fava branca; sua madeira serve apenas para o fogo"'. Interpretando Gabriel SoARes de Souza, esereve Hoenne (1937 - 296): "Na bibliografia sôbre a flora baiana, infelizmente nada deparamos que nos permitisse esclarecer esta espécie. Incontestàvelmente, "Geremari" é a mesma cousa que "Jurema" e "Juremari" e RECORD nos dá com tais nomes o Pithecolobium tortum Mart., que é uma árvore dos sertões da Bahia, armada de espinhos fortes, que produz legumes tortos, com sementes duras'.

CORIMATAN - Mesmo que CURIMATã. Beneditinos, Piauí.

CURIMATAN - Mesmo que CURIMATÃ. Luzilândia, Piauí.

CURYMATAN - Peixe introduzido, no açude público "Parazinho" (Granja, Ceará), pelo eng. José Rodrigues Ferreira, seu construtor, que mandou apanhar o peixe no rio Coreaú (Rers, 1920: 124). Mesmo que CURIMATÃ.

CRUMATAN - Mesmo que CURIMATã. Piracuruca, Piauí.

GITUBARÃ - Corruptela de JUTUBARANA, em Acopiara, Ceará, onde, em 1947, a produção orȩou em $520 \mathrm{k}$, no valor de Cr\$2.080,00.

GORGORÓ - Peixe de couro. Beneditinos, Piauí.

GRAGIOLA - Corruptela de GRAVIOLA. Esperantina e Luzilândia, Piauí.

GRAJARÚ - Peixe dágua doce. Cocó, Fortaleza, Ceará. (AvôNIMO, 1928: 17).

GRANJIOLA - Teresina, Piauí. Mesmo que GRAVIOLA.

HUlulư - Peixe dágua doce, em Prainha do Aquiraz, Ceará (Anônimo, 1928: 16).

IHÚ - Peixe dágua doce. Cocó, Fortaleza, Ceará. Provàvelmente mesmo que JEJÚ. Apanhado "em parte mais profunda e perto das margens". (ANôNIMo, 1928: 17). 
JACURANã - Peixe dágua doce. Cocó, Fortaleza, Ceará. (AnôNIMO, 1928: 17).

LISO - Peixe de couro. Beneditinos, Piracuruca e Porto, Piauí.

MANDÍ BOUCÃO - Peixe de couro. Beneditinos, Piauí.

MANDÍ SERRA - "Lagoa da Feitoria, Oeiras, Piauí. Fam. Doradidae” (Oliverra e Silva, 1949). Provàvelmente o mesmo que MANDí BICUDO, Hassar affinis (Steind).

MANDÍ VERDADEIRO - "Lagoa da Feitoria, Oeiras, Piauí; fam. Pimelodidae” (Oliveira e Silva, 1949).

MANDIBÁ - Piauí (Barreto \& Cavalcanti, 1948: 537). Provàvelmente o mesmo que MANDIBÊ ou MANDUBE.

MANDINHO - Peixe do Poço da Cruz, Rio Moxotó, mun. Moxotó, Pernambuco. Mesmo que Mandí.

MANÊ OIÃO - Designação de TUCUNARÊ no aȩude público "Cruzêta", Acarí, Rio Grande do Norte.

MARTRINCHAN - "Peixe do Rio Grande, afluente do São Francisco" (CAZAL, 1933: 167). Provàvelmente mesmo que MATRINCHÃ.

MULECA - Nome dado à TRAÍRA pelos pescadores do Rio Mossoró, mun. Mossoró, Rio Grande do Norte (GUERRA, 1948 (?), 11).

PACUM - Piracuruca, Piauí. Provàvelmente mesmo que PACÚ.

PEIXE PAVÃO - Nome dado ao TUCUNARÉ nas proximidades de Fortaleza, Ceará (informação do Sr. Oceano Atlantico Linhares, ex-téenico do Serviço de Piscicultura).

PENIMA - Peixe dágua doce. Cocó, Fortaleza, Ceará. “Apanhado na profundidade de 0,50 m 1,20 m (Anônimo, 1928: 17-18).

PIÁU BANANA - Na Lagoa da Feitoria (Oeiras, Piauí), corresponde a Schizodon fasciatus Agassiz. Noutros locais do Piauí, esta espécie é conhecida por PIÁU DE VARA.

PIHAU - Peixe introduzido no açude público "Parazinho" (Granja, Ceará), em 1917, procedente do Rio Coreaú, pelo eng. José Rodrigurs Ferreira (Reis, 1920: 124), construtor daquele reservatório. Mesmo que PIAÚ.

PIRANHA PAPO DE FÔGO - Açude público "Cruzêta", Rio Grande do Norte. Serrasalmus sp.

PIRAPEMBA - Rio Parnaíba (Cazal, 1833: 215). Segundo Ihering (1940 : 631), PIRAPEMA é "denominação amazonense do "Camarupim" (peixe do mar); aí também foi referida a aplicação de nome semelhante 
a um grande peixe da mesma família que o SORUBHM. Já advertimos sôbre "Camarupim" que Maregrave registra como um peixe diferente, com o nome "PIRAPEMA".

PORCA - Na Lagoa da Feitoria (Oeiras, Piauí), designação de Platydoras costatus (L), conhecida noutros pontos do Piauí por GRAVÍOLA, GRANJIOLA e GRAGIOLA (verificaȩão de OLIveira e SiLVA, 1949). Segundo êste autor, naquela Lagoa, nos meses de setembrooutubro, 1949, " $99 \%$ das PORCAS estavam parasitadas por um Cestóide, localizado na parte mediana do intestino, formando verdadeiro novelo em tôda luz do tubo intestinal".

SAƯNA - Limoeiro do Norte, Ceará. Em 1947, apanhados 50 k, no valor de $\mathrm{Cr} \$ 250,00$.

SAROBIM - Peixe do Rio Parnaíba (Cazal, 1833: 315).

SARUBí - Miguel Alves, Piauí. Produção de 1946: $5.000 \mathrm{k}$, no valor de Cr\$ 20.000,00: produção de 1948: $12.000 \mathrm{k}$, no valor de Cr\$ $48.000,00$.

TAÍRA - Miguel Alves, Piaí. Mesmo que TRAIRA. Produziu aquele município, em 1948, um total de $3.000 \mathrm{k}$, no valor de Cr\$ 9.000,00.

"TARTARUGA" - "Variedade de peixe do açude Cedro, Ceará" (Souza, 1927: 88). Trata-se de um réptil, e não de um peixe.

"TRACAJA" — "Variedade de peixe do açude Cedro, Ceará" (Souza, 1927: 88). Trata-se de um réptil, e não de um peixe.

\section{BIBLIOGRAFIA}

ANONIMO, 1928 - A Vida das Confederações Estaduais e das Colônias de Pescadores, "A Voz do Mar", Rio de Janeiro 7 (76) : 11-21.

BARRETO, J. DE BARROS \& CAVALCANTI, T. A. de A., 1948 - Problema alimentar do Maranhão e Piauí subsídio para o seu estudo, "Mem. Inst. Oswaldo Cruz", Rio de Janeiro 46 (3) : 532-550.

CALDAS, D. M., 1867 - "Relatório da viagem feita de Teresina até a cidade da Parnaíba pelo rio do mesmo nome, inclusive todo o seu delta, - por ordem do Dr. Adelino Antonio de Luna Freire, presidente do Piaû", Tip. da Impresa, Teresina, pp. 1-126.

CAZAL, M. A. do - "Corographia brasilica ou Relação historica-geographica do Brasil”, Edit. E. e H. Laemmert, Rio de Janeiro, pp. 1-335.

DEPT. EST. DE ESTATíSTICA DO CEARÃ, ... - “Pesca no Ceará em 1947", Sec. Estat. Eeôn., Fortaleza, 26 pp. (mimeografada).

DEPT. EST. DE ESTATISTICA DO PIAUi, ... - Boletins municipais de estatística, Terezina.

GUERRA, J. M. G., 1948 (१) - "A Pesca no rio Mossor6", "Bol. Bibliográfico", Bibl. Publ. e Mus. Mun., Mossoró, Rio Gr. do Norte (mimeografado). 
HOEHNE, F. C., 1937 - "Botânica e Agricultura no Brasil (Seculo XVI) (Pesquisas e contribuições)", Cia. Edit. Nac., S. Paulo, Bibl. Pedag6gica Brasil., Série 5.", "Brasiliana", vol. 71 pp. 1-410.

IHERING, R. V., 1940 - "Dicionário dos Animais do Brasil", Diret. Publicidade Agric., Secret. Agric., S. Paulo, pp. 1-899.

MENEZES, R. S. de, .... - Lista dos nomes vulgares de peixes de águas doees e salôbras na zona sêca do Nordeste e Leste do Brasil (a publicar in "Arq. Mus. Nacional", Rio de Janeiro).

OLIVEIRA E SILVA, S. IL. de, 1949 - "Relatório da viagem a lagoa da Feitoria, Piauí, com o fim de transportar exemplares vivos de "Curvina", Plagioscion, squamosissimus (Heckel), para o Pôsto de Piscicultura de Lima Campos”, 12 pp. (datilografado), 1 mapa, 3 fotografias, 1 desenho no texto.

REIS, A., 1920 - "Obras Novas Contra as Sêcas, de S-IX-1915 a S1-X-1918", Relat. apresent. ao Min. Tavares Lyra, do Min. Viação e Obras Públicas, Impr. Nac., Rio de Janeiro, pp. i-xlviii + 1-246.

SOUSA, E. de, 1927 - "Memória sôbre o município de Quixadá (Estado do Cearâ)", Tip. Moderna, Fortaleza, pp. 1-132.

SOUSA, GABRIEL SOARES de, 1945 - "Noticia do Brasil", Introd., coment. e notas pelo Prof. Pirajá da Silva, Livr. Martins Edit., S. Paulo, Bibl. Hist. Brasil., XVI, 1 : 1-351; 2 : 1-354. 